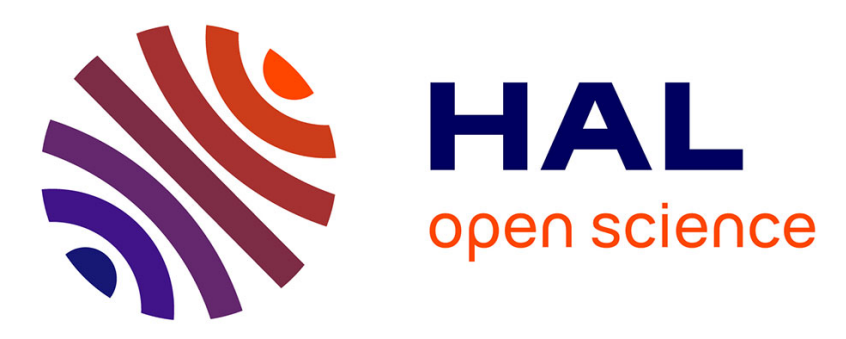

\title{
In-Vitro Broad Band Impedance Study of a Biochemical Reaction under Nanopulses: Electrode Impedance as a Reaction Sensor
}

Olivier Meyer, Cédric Gilbert, Arlette Fourrier-Lamer, Hubert Cachet

\section{- To cite this version:}

Olivier Meyer, Cédric Gilbert, Arlette Fourrier-Lamer, Hubert Cachet. In-Vitro Broad Band Impedance Study of a Biochemical Reaction under Nanopulses: Electrode Impedance as a Reaction Sensor. Journal of The Electrochemical Society, 2014, 161 (4), pp.B62-B69. 10.1149/2.074404jes . hal-01018334

\section{HAL Id: hal-01018334 \\ https: / hal.sorbonne-universite.fr/hal-01018334}

Submitted on 18 Jul 2014

HAL is a multi-disciplinary open access archive for the deposit and dissemination of scientific research documents, whether they are published or not. The documents may come from teaching and research institutions in France or abroad, or from public or private research centers.
L'archive ouverte pluridisciplinaire HAL, est destinée au dépôt et à la diffusion de documents scientifiques de niveau recherche, publiés ou non, émanant des établissements d'enseignement et de recherche français ou étrangers, des laboratoires publics ou privés. 


\title{
In-vitro broad band impedance study of a biochemical reaction under nanopulses: electrode impedance as a reaction sensor.
}

\author{
Olivier Meyer $^{\mathrm{a}, \mathrm{d}}$, Cédric Gilbert ${ }^{\mathrm{a}, \mathrm{d}}$, Arlette Fourrier-Lamer ${ }^{\mathrm{b}, \mathrm{d}}$, Hubert Cachet ${ }^{\mathrm{c}, \mathrm{d}, \mathrm{e}}$
}

a) Sorbonne Universités, UPMC Univ Paris 06, Supélec, Univ Paris Sud 11, CNRS, UMR 8507, LGEP, 11, rue Joliot Curie, F-91192 Gif-sur-Yvette, France.

b) Sorbonne Universités, UPMC Univ Paris 06, UR2 L2E,-Laboratoire d'Electronique et Electromagnétisme F-75005, Paris.

c) CNRS, UPR 15, Laboratoire Interfaces et Systèmes Electrochimiques, 75005, Paris, France

d) Sorbonne Universités, UPM, Univ Paris 06, 4 Place Jussieu, 75005 Paris, France

\begin{abstract}
This work is a first attempt to investigate the effects of ultra wideband (UWB) electromagnetic pulses upon a reaction of biological interest involved in neuronal communication, the hydrolysis of acetylcholine chloride $(\mathrm{AChCl})$ catalyzed by the acetylcholine esterase enzyme (AChE). This study is based on broadband impedance measurements performed with the same cell in the range $40 \mathrm{~Hz}-4 \mathrm{GHz}$ within 10 s, without or with superimposed nanopulses, as a function of the elapsed time. The response above 1 $\mathrm{MHz}$ was assigned to the conductive and dielectric properties of the aqueous solution containing $\mathrm{AChCl}$ and $\mathrm{AChE}$ filling the cell. The response below $100 \mathrm{kHz}$ was due to electrode impedance at the golden cell wall/solution interfaces. This low frequency behaviour was ascribed to a dynamical adsorption-desorption process of $\mathrm{AChCl}$ in equilibrium with the bulk. The electrode impedance behaves as a sensor of the actual bulk concentration of $\mathrm{AChCl}$ when the reaction is in progress. From impedance spectra analysis it was shown that superimposed nanopulses slowed down the hydrolysis reaction, the stronger this effect the higher the pulse repetition rate. The inhibition of the reaction could be related to a lesser catalytic activity of AChE possibly through a conformational change induced by nanopulses.
\end{abstract}

Key words: broadband impedance, nanosecond pulses, acetylcholine hydrolysis, adsorption

e E-mail: hubert.cachet@upmc.fr 


\section{Introduction}

There is a large interest for a better understanding of the interactions between electromagnetic waves and biological systems, for the thermal and non thermal effects [1]. For the human body and radiations in the range $100 \mathrm{kHz}-300 \mathrm{GHz}$, it is admitted that above a threshold of $4 \mathrm{~W} / \mathrm{kg}$ the temperature regulation can be strongly disturbed [2]. Around the world, people are immersed in more or less intense electromagnetic fields due to the emergence of global communication systems using radiofrequencies (hertzian TV, cellular telephone), but also the development of radar technologies, high voltage power lines. Thermal effects can be limited by imposing recommendations about the acceptable thresholds for workers or public people. But another effects are suspected, like a possible interaction between electromagnetic radiations and some mechanisms involved in brain activity $[3,4]$.

The main difficulty encountered in in vitro and in vivo studies is to master the electromagnetic field. At our knowledge, there is no system allowing the control of the electromagnetic field through a biological substrate without modifying its confinement. Furthermore, most of the in vitro studies are carried out at the cell level $[5,6]$. The present work is dealing with the study at the molecular level of a biochemical reaction and how the latter can be disturbed by applying a pulsed electromagnetic field.

The reaction under study is hydrolysis of an acetylcholine chloride substrate in the presence of acetylcholinesterase leading to the formation of choline chloride and acetic acid, as depicted in Figure 1. Acetylcholine is the main neurotransmitter in the human body implied in the communication between neurones. These species present an ionic character. Our purpose is to investigate the microthermal, athermal or subthermal mechanisms of a biochemical kinetics brought by application of a pulsed electromagnetic field, stressing upon the effect of energy threshold and not on that of absorbed radiofrequency power [7-9]. Using very narrow pulses allows to maintain thermal equilibrium inside the sample, to rule out any thermal effect 
[9-12]. To achieve this goal, a broad-band impedance technique was used in the range $40 \mathrm{~Hz}$ $4 \mathrm{GHz}$, allowing a few nanoseconds ultra wideband (UWB) pulses to be superimposed at a fixed repetition rate. A full spectrum being recorded in 10 seconds it is possible to follow the modifications undergone by the substrate as a function of the elapsed time.

In this work, the experimental technique for broad band impedance measurements will be firstly presented, followed by a short description of the biochemical reaction. It will be shown that impedance data, recorded at different times and with or without superimposed pulses, can be analyzed by considering bulk dielectric and conductive properties above $1 \mathrm{MHz}$, electrode impedance effects due to adsorption process at frequencies below $100 \mathrm{kHz}$.

Figure 1

\section{Experimental}

\section{2-1 Broad band (40Hz-4GHz) impedance spectroscopy. Quasi-static approximation.}

The experimental set-up (Fig. 2) is composed of two impedance analyzers (Agilent 4291A, Agilent 4294A) and a network analyzer (Agilent PNA-C) compatible with the coaxial discontinuity characterization cell which allows us to get analytical impedance data from 40 $\mathrm{Hz}$ to $4 \mathrm{GHz}$ with 350 frequency points within a short sweep (10s) [7,8]. The high frequency limit is imposed by the high dielectric permittivity of water with which we are concerned in the present study. A short circuited coaxial line (APC7 connectors) is terminated by a cylindrical gap filled with the unknown electrolytic solution. A theoretical analysis of the electromagnetic field in the line and in the gap was made and all higher order waves excited at the discontinuity were taken into account. The problem was treated by the mode-matching method in which the fields on each side of the discontinuity are expanded in an infinite series of modes matched across the boundary to preserve continuity. The solution of the field equation yields the equivalent impedance without any restriction [13]. As long as the 
evanescent mode condition is verified, the empty cell can be simply characterized by a capacitance $\mathrm{C}_{\text {cell }}$ which can be determined by using pure water. Bubble formation due to water electrolysis was observed when using a $0.5 \mathrm{~V}$ rms $a c$ excitation signal (i.e. $1.4 \mathrm{~V}$ peak-topeak). Consequently the applied voltage for impedance measurements was limited to $20 \mathrm{mV}$ rms in order to avoid such water oxido-reduction within the cell. The validity of the broadband impedance measurements in these conditions of low excitation level was verified by checking the response of standard liquids, with a precision better than $5 \%$ over all the frequency range explored [13].

The cylindrical measurement cell was submicron polished and gold plated in order to minimize a possible corrosion reaction in the presence of chloride ions. On the coaxial side, a Plexiglas circular plug was disposed to make the cell watertight. The volume of liquid needed for electrical measurements was about $0.15 \mathrm{~cm}^{3}$ (Fig. 3).

The measurement cell was excited alternately by the field of high amplitude (delivered by a pulse generator) and the low level measurement fields supplied by the impedance and network analyzers. The switching system can support up to $4 \mathrm{kV}$ pulse. The pulse generator was a Kentech- $1 \mathrm{kV}$ generator (pulses $200 \mathrm{~ns}$, rise time $<1 \mathrm{~ns}$ ). The pulses were applied in the form of pulse trains with a repetition frequency from 10 to $100 \mathrm{~Hz}$ with periods of 10 seconds (i.e. 100 pulses or 1000 pulses during 10 seconds, respectively). The amplitude of applied pulses was limited to $330 \mathrm{~V}$. The electric field was estimated around $160 \mathrm{kV} / \mathrm{m}$ at the interface between electrode and liquid, with a max higher than $450 \mathrm{kV} / \mathrm{m}$ at the periphery of the central core. This sequence is followed by 10 seconds of impedance measurement without applied pulses, and so on, for a total experimental time of 1 to 2 hours.

Impedance spectrum simulations were done on the basis of electrical equivalent circuits involving complex elements not reducible to conventional circuit components. All the parameters corresponding to a given equivalent circuit were determined by means of a non 
linear least square procedure, using a home-made simplex program based on the Nelder and Mead down-hill strategy [14]. The optimal set of adjustable parameters was obtained by minimizing the least square criterion over all the sampled frequencies, considering the real and imaginary parts of the measured impedance as independent observations, weighted by assuming an a priori $1 \%$ error on impedance modulus.

Figures 2,3

\section{2-2 Presentation of the biochemical reaction.}

The investigated biochemical reaction is the hydrolysis of acetylcholine chloride ( $\mathrm{AChCl}$ ), which is the substrate, in the presence of the acetylcholine esterase enzyme (AChE) (Fig.1). The role of AChE is essential in the rate of degradation of $\mathrm{ACh}$. The products formed are choline chloride $(\mathrm{ChCl})$ and acetic acid (AA). Ach is one of the first neurotransmitters discovered. It is present in the central and peripheral nervous system.

Basically, during the transmission process of information between neurons, ACh is sent through the channel connecting two synaptic neurons. Upon ACh arrival at the end of the channel, the molecule clings to the cholinergic receptor (nicotinic and muscarinic receptors). Once the transmission of information is over, ACh is released into the synaptic channel and is degraded by the AChE enzyme.

The hydrolysis reaction producing acetic acid as a by-product has a strong tendency to acidify the reaction medium and thus to reduce its $\mathrm{pH}$. The effectiveness of the enzyme is high for a $\mathrm{pH}$ between 7 and 8 . A pH buffer is then required to maintain a constant $\mathrm{pH}$ around 7 . Note that at neutral $\mathrm{pH}$ acetic acid is fully dissociated.

All the chemicals, $\mathrm{AChCl}, \mathrm{ChCl}, \mathrm{AA}$, were purchased from Aldrich. $\mathrm{AChE}$ (Aldrich) was provided at the concentration $5 \mathrm{u} / \mathrm{ml}$. It has an enzymatic activity greater than or equal to 1,000 
units per milligram. The solution under test was buffered at $\mathrm{pH}=7$ (phosphate buffer ref. $\mathrm{J} / 2850 / 15$ from Fisher Scientific).

The bovin serum albumin (BSA) from Biochemika was used to stabilize AChE during the catalysis process at a concentration of $1 \mathrm{mg} / \mathrm{cm}^{3}$. Moreover, BSA is known to prevent enzyme adhesion to the cell wall.

The molar concentration of $\mathrm{AChCl}$ was chosen $50 \mathrm{mM}$ in order to slow down the hydrolysis reaction rate to be able to sample the state of the system at a sufficient number of times by means of the broadband impedance spectroscopy equipment described above.

\section{Results and data analysis}

\section{3-1 Experimental impedance/admittance spectra}

Figure $4 \mathrm{a}$ shows the Nyquist representation of a set of impedance spectra recorded at increasing reaction times in the $40 \mathrm{~Hz}-4 \mathrm{GHz}$ frequency range and in the absence of superimposed pulses. Two capacitive contributions are clearly pointed out. At high frequencies, above $1 \mathrm{MHz}$, the capacitive loop arises from the conductive and dielectric properties of the bulk solution in ef the cell. It corresponds to the parallel combination of the bulk resistance of the solution $R_{\text {bulk }}$ and the frequency dependent cell capacitance $C_{\text {bulk }}$, as the product of the geometric cell capacitance $\mathrm{C}_{\text {cell }}$ with the relative complex dielectric permittivity of the aqueous solution filling the cell. $\mathrm{R}_{\text {bulk }}$ is related to the $d c$ conductivity $\sigma_{\mathrm{dc}}$ of the solution:

$$
R_{b u l k}=\frac{1}{\sigma_{d c}} \frac{\varepsilon_{0}}{C_{c e l l}}
$$


where $\varepsilon_{0}=8.85410^{-12} \mathrm{~F} / \mathrm{m}$. The low frequency part also corresponds to a parallel resistancecapacitance circuit, the resistance in parallel being very large. The high frequency loop is not dependent on the reaction time, at reverse what happens for the low frequency part. Better information on the latter can be gained by considering the admittance representation as depicted in figure $4 \mathrm{~b}$. It can be seen that at $\mathrm{t}=0$, below $1 \mathrm{MHz}$, the admittance plot is a semicircle with the centre below the real axis. As the reaction time increases, the semicircle is more and more flattened and becomes distinctly asymmetric after one hour. This example of impedance data is typical of all the impedance data obtained without or with superimposed pulses, as illustrated in figure 5 . With respect to the initial state at time 0 , and after a reaction time of 70 minutes, the modification of the low frequency loop is particularly accentuated in the absence of pulses and less and less important when increasing the repetition rate of the pulses.

Figures $4 \mathrm{a}, 4 \mathrm{~b}, 5$

\section{3-2 Electrical circuit for impedance data analysis}

The simplest equivalent electrical circuit (EEC) to represent impedance data is the series

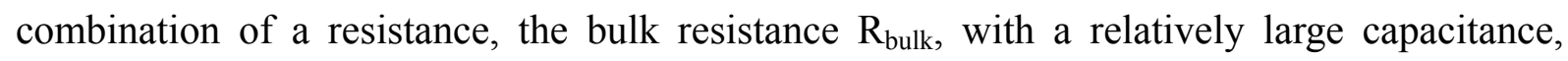
arising from the interface between the metal electrodes and the electrolyte solution, the socalled double layer capacitance $\mathrm{C}_{\mathrm{dl}}$ [15]. In the ideal case, $\mathrm{C}_{\mathrm{dl}}$ is the differential capacitance formed between the charged plane at the metal surface and the ionic space counter charge in the electrolyte. The reorganization time of the ionic charge is considered to be very fast yielding $\mathrm{C}_{\mathrm{d} l}$ to be frequency independent. Obviously such an oversimplified circuit is not sufficient to represent the data correctly. As said above, the bulk resistance has to be shunted by the dielectric capacitance of the cell $\mathrm{C}_{\text {bulk }}$, which depends on all the species present in the aqueous electrolyte, solvent molecules and various polar solutes. It is important to note that 
$\mathrm{R}_{\text {bulk }}$ is determined by the contribution of all the ionic species to the solution conductivity; $\mathrm{R}_{\text {bulk }}$ is a frequency independent quantity in the frequency domain explored in this work as experimentally stated for aqueous electrolyte solutions [16-21].

As depicted in the admittance representation, a single time constant $\mathrm{R}_{\text {bulk }} \mathrm{C}_{\mathrm{dl}}$ is not sufficient to account for the data. A distribution of time constants has to be taken into account, from a symmetric distribution at short reaction times to an asymmetric one after a few tens of minutes. As $\mathrm{R}_{\text {bulk }}$ is frequency independent, the distribution of time constants is necessarily due to the electrode capacitance. In the absence of faradic reactions, i.e. implying an electron transfer between the metal electrode and donor/acceptor species in the solution, the probable mechanism involved is a time-dependent adsorption process yielding a frequency dispersion of the electrode capacitance $[22,23]$. Such a process was initially modelled by W. Lorenz [24] some time ago. The model is based on an adsorption-desorption equilibrium between the electrode surface and the volume of the solution in contact:

$$
[\mathrm{AChCl}]_{\text {adsorbed }} \leftrightarrow[\mathrm{AChCl}]_{\text {bulk }}
$$

It means that the surface concentration is the image of the bulk concentration. From the static point of view, a fraction $\theta$ of the electrode surface is covered by the adsorbed species and becomes electrically inactive. The uncovered part is responsible for a double layer capacitance $(1-\theta) \cdot C_{\mathrm{dl}}$ where $\mathrm{C}_{\mathrm{dl}}$ would be the response of the bare electrode, i.e. without adsorbed species. From a dynamic point of view, the surface coverage $\theta$, and then the electrode charge, can be modulated by the $a c$ potential and by the kinetics of the adsorptiondesorption process.

According to Lorenz, any charge variation $\Delta \mathrm{q}$ of the electrode is assumed to depend only on electrode potential $\mathrm{E}$ and on surface coverage $\theta . \Gamma\left(\Gamma_{\mathrm{m}}\right)$ being the actual (maximal) surface concentration of the adsorbed species, with $\theta=\Gamma / \Gamma_{\mathrm{m}}$, it reads: 


$$
\frac{d(\Delta q)}{d t}=\left(\frac{\partial(\Delta q)}{\partial E}\right)_{\Gamma} \cdot \frac{d E}{d t}+\left(\frac{\partial(\Delta q)}{\partial \Gamma}\right)_{E} \cdot \frac{d \Gamma}{d t}
$$

Dynamics of the process is contained in the $\mathrm{d} \Gamma / \mathrm{dt}$ term, which can be written in the small perturbation approximation, $\mathrm{c}$ being the bulk concentration of the adsorbed species:

$$
\frac{d \Gamma}{d t}=v_{E} \cdot \Delta E+v_{c} \cdot \Delta c+v_{\Gamma} \cdot \Delta \Gamma
$$

$\Delta \mathrm{c}$ and $\Delta \Gamma$ are time-dependent functions which are determined by the differential diffusion equation (Eq.5a) coupled to the condition of flux conservation (Eq.5b), namely:

$$
\begin{aligned}
& \frac{\partial \Delta c}{\partial t}=D \cdot \frac{\partial^{2} \Delta c}{\partial x^{2}} \\
& D \cdot\left(\frac{\partial \Delta c}{\partial x}\right)_{x=0}=\frac{d \Gamma}{d t}
\end{aligned}
$$

$\mathrm{D}$ is the diffusion coefficient of the species involved in the adsorption-desorption process. Within these conditions, for a sinusoidal potential modulation, according to literature [24-26], the electrode capacitance is a complex quantity which is expressed as:

$$
C_{a d}(\omega)=C_{\infty}+\frac{\left(C_{0}-C_{\infty}\right)}{1+j \omega \tau_{H}+\sqrt{j \omega \tau_{D}}}
$$

In this expression, $\mathrm{C}_{\infty}$ is the high frequency limit of $\mathrm{C}_{\mathrm{ad}}$ and $\mathrm{C}_{0}$ the low frequency one: the larger $\mathrm{C}_{0}$ is, the lower the surface coverage $\theta$ is. $\tau_{\mathrm{D}}$, the characteristic time for the mass transport step, is defined by:

$$
\tau_{D}=\left(\frac{v_{c}}{v_{\Gamma}}\right)^{2} \cdot \frac{1}{D}
$$


and $\tau_{\mathrm{H}}$, the time characteristic of the heterogeneous adsorption-desorption step, reads:

$$
\tau_{H}=\frac{-1}{v_{\Gamma}}
$$

This allows us to propose the complete EEC to be used to fit the experimental impedance spectra in the frequency range $40 \mathrm{~Hz}-1 \mathrm{GHz}$ as given in figure 6.

Figure 6

In this scheme, $\mathrm{R}_{\text {bulk }}$ is defined by Eq. 1 and the frequency dependent dielectric capacitance of the cell $\mathrm{C}_{\text {bulk }}(\omega)$ is defined by Eq.8:

$$
C_{\text {bulk }}(\omega)=C_{\text {cell }} \cdot \varepsilon(\omega)
$$

After calibration with pure water, it was found $\mathrm{C}_{\text {cell }}=0.078 \pm 0.002 \mathrm{pF}$. The relative complex dielectric permittivity $\varepsilon(\omega)$ of the electrolyte medium is assumed to follow a Debye type relaxation:

$$
\varepsilon(\omega)=\varepsilon_{\infty}+\left(\varepsilon_{s}-\varepsilon_{\infty}\right) /\left(1+j \omega \tau_{H F}\right)
$$

with the limit at $\omega=0: C_{\text {bulk }}(\omega=0)=C_{\text {cell }} \cdot \varepsilon_{\mathrm{s}}, \varepsilon_{\mathrm{s}}$ being the relative static dielectric permittivity of the solution filling the cell. The admittance $Y_{a d}$ of the $\left(R_{a d}, C_{a d}\right)$ parallel circuit is:

$$
Y_{a d}=1 / R_{a d}+j \omega C_{a d}(\omega)
$$

The admittance $\mathrm{Y}_{\text {bulk }}$ of the $\left(\mathrm{R}_{\text {bulk }}, \mathrm{C}_{\text {bulk }}\right)$ circuit is:

$$
Y_{b u l k}=1 / R_{b u l k}+j \omega C_{b u l k}(\omega)
$$


Finally the expression for the impedance $Z(\omega)$ to be compared to experimental data over the $40 \mathrm{~Hz}-1 \mathrm{GHz}$ frequency range is given by:

$$
Z(\omega)=1 / Y_{a d}+1 / Y_{b u l k}
$$

Remarkably $Z(\omega)$ only depends on eight parameters over more than seven decades of frequency, which are: $\mathrm{R}_{\text {bulk }}, \tau_{\mathrm{HF}}, \varepsilon_{\mathrm{s}}, \mathrm{R}_{\mathrm{ad}}, \mathrm{C}_{\infty}, \mathrm{C}_{0}, \tau_{\mathrm{H}}, \tau_{\mathrm{D}}$. For the most of the experiments, it has been found that $\tau_{\mathrm{H}}$ is not significant, meaning that the heterogeneous adsorption-desorption step was very fast, reducing to seven the number of relevant parameters. The values of these parameters were found by applying the non linear least square fitting procedure introduced in the experimental section. The function defined by Eq. 12 is able to represent the experimental impedance spectra over the full frequency range explored at a quality level around $1 \%$, expressed as a standard reduced deviation (S.D.) with respect to a $1 \%$ relative error assumed on impedance modulus.

\section{3-3 Fitted parameters and results}

All the fitted parameters are gathered in Tables 1 to 4 , corresponding to the four sets of data $v s$. the reaction time, without added pulses (Table 1), and with superimposed UWB pulses at different repetition rates of 10,50 and $100 \mathrm{~Hz}$ (Tables 2-4 respectively). The main features of the results are illustrated in the figures 7 to 10 .

Figure 7 shows the relative variations of the bulk resistance $R_{\text {bulk }}$ with the reaction time. $R_{\text {bulk, }}$ which corresponds to the dc conductivity of the electrolyte solution, is of the order of 0.90 $\mathrm{Sm}^{-1}$ as expected for the phosphate buffer solution. The same tendency is observed whatever the experimental conditions with a systematic increase of 3-5\% during the first minutes and a quasi plateau at times longer than 20-30 minutes. It means a decrease in the bulk 
concentration of free ions. The decrease is the largest in the absence of perturbation, becoming progressively smaller when the repetition rate is increased. In connection with the behaviour of $\mathrm{R}_{\text {bulk, }}$, it is worthwhile to look at the variations of the parallel resistance $\mathrm{R}_{\mathrm{ad}}$. The physical origin of $\mathrm{R}_{\mathrm{ad}}$ is a possible parasitic faradic reaction, which could be a weak corrosion process of the gold electrode in the presence of chloride ions. Such a corrosion process was observed previously when the measurement cell was made of brass. It is remarkable to note that in the absence of pulses $R_{a d}$ tends rapidly towards infinite values. On the contrary, when pulses are applied to the cell, finite values are kept for $\mathrm{R}_{\mathrm{ad}}$ suggesting that less chloride ions were consumed in the chemical reaction. Then the increase in $\mathrm{R}_{\text {bulk }}$ would be related to the diminution of the bulk concentration of free chloride ions.

The dramatic effect of diffusion on the adsorption process is depicted in the figure 8 . During the first thirty minutes, the diffusion time $\tau_{\mathrm{D}}$ is of the order of $1 \mathrm{~ms}$. At longer reaction times, there is a net increase, the larger the increase is the lower the repetition rate is. Note that in the absence of pulses the increase in $\tau_{\mathrm{D}}$ is about sixty times, indicating that the concentration of species involved in the adsorption process is depleted near the electrode surface.

\section{Figures 7,8}

The same behaviour is observed for the static value of the electrode capacitance $\mathrm{C}_{0}$, as shown in the figure 9. The $\mathrm{C}_{0}$ values are practically constant, around $1-2 \mu \mathrm{F}$, up to 20 minutes and then increase at longer times. As for $\tau_{\mathrm{D}}$, the larger the increment of $\mathrm{C}_{0}$ is the lower the pulse repetition rate is, the maximum amplitude being always obtained in the absence of pulses. The variations of $\mathrm{C}_{0} v s$. the reaction time $\mathrm{t}_{\mathrm{R}}$ can be modelled by a sigmoid curve, for instance of the Boltzman type: 


$$
C_{0}\left(t_{R}\right)=C_{\lim }+\frac{C_{i n i}-C_{\text {lim }}}{1+\exp \left(\frac{t_{R}-t_{1 / 2}}{d t_{R}}\right)}
$$

where $C_{i n i}$ and $C_{\text {lim }}$ are the initial and limiting values of $C_{0}$ respectively; $t_{1 / 2}$ is the reaction time for which $\mathrm{C}_{0}=\left(\mathrm{C}_{\mathrm{lim}}+\mathrm{C}_{\mathrm{ini}}\right) / 2$ and $\mathrm{dt}_{\mathrm{R}}$ characterizes the steepness of the sigmoid curve. The parameters obtained by fitting equation (13) to the data of the figure 9 are given in Table 5 . The rise time is longer, and then the reaction efficiency smaller, when the repetition rate is increased from 0 to $50 \mathrm{~Hz}$. Note that for $100 \mathrm{~Hz}$ modulation rate the reaction is practically inhibited.

High frequency measurements provide additional information about the chemical changes in the bulk solution. From literature, the dielectric relaxation time of water is about 8 ps (i.e. 20 $\mathrm{GHz}$ ) at room temperature [27]. At frequencies $\leq 1 \mathrm{GHz}$, water molecules do not give rise to measurable relaxation effect and the dielectric properties of water are fully characterized by its static permittivity, eventually modified due to solvation and/or steric effects in the presence of various solutes. The values found for the $\varepsilon_{\mathrm{s}}$ parameter (Tables 1-4) are in agreement with a static dielectric permittivity around 78 , close to the value of pure water, without noticeable variation during experiments. The values of relaxation times deduced from spectra analysis (see Tables 1-4) lie in the range 18-20 ps, much larger than the characteristic time of pure water. This can be assigned to the contribution of polar species present in the aqueous solution under study, for instance $\mathrm{AChCl}, \mathrm{ChCl}$. In figure 10 , the values of $\tau_{\mathrm{HF}}$ are plotted $v s$. the reaction time, in the absence and in the presence of pulses. There is a systematic evolution from an initial value at $19.5 \mathrm{ps}$ to a limiting one, at $18.5 \mathrm{ps}$. The difference is small but significant. From additional experiments in the absence of AChE (see Table 6), it was possible to measure the relaxation time for $\mathrm{AChCl}(19.4 \mathrm{ps}), \mathrm{ChCl}(18.6 \mathrm{ps})$ and for $\mathrm{ChCl}+\mathrm{AA}(19.0$ 
ps). These values are reported in the figure 10, allowing to conclude that $\mathrm{AChCl}$ is progressively transformed into $\mathrm{ChCl}$.

Figures 9, 10

\section{Information on the reaction kinetics}

The above results show that broadband impedance measurements are able to provide information on the changes in the bulk concentration of the species involved in the hydrolysis reaction of $\mathrm{AChCl}$. The low frequency part of the impedance spectrum, relative to electrode impedance, is the main tool for probing the extent of the hydrolysis reaction. Initially, as wall adhesion of $\mathrm{AChE}$ is prevented by $\mathrm{BSA}$, it can be assumed that only $\mathrm{AChCl}$ is adsorbed at cell electrodes. In the absence of surface saturation effect, an equilibrium is established between the surface and bulk concentrations of $\mathrm{AChCl}$. As the surface concentration of the adsorbed species is reflected by the low frequency limit of the adsorption capacitance $\mathrm{C}_{0}$, a sensor of the actual $\mathrm{AChCl}$ bulk concentration during hydrolysis reaction can be achieved by measuring $\mathrm{C}_{0}$ as a function of the reaction time $t_{R}$. Then a relative extent of the hydrolysis reaction can be modelled in principle from the $\mathrm{C}_{0}\left(\mathrm{t}_{\mathrm{R}}\right)$ response. To do that it is necessary to know at what time $t_{C R}$ the reaction would be complete. In our experimental conditions, $t_{\mathrm{CR}}$ can be estimated to be around 60 minutes, from the $\mathrm{C}_{0}\left(\mathrm{t}_{\mathrm{R}}\right)$ plot in the absence of pulses. This conclusion is justified by the presence of a plateau of $\mathrm{C}_{0}$ around $\mathrm{t}_{\mathrm{R}}=60 \mathrm{~min}$, followed by a strong increase in $\mathrm{C}_{0}$ at longer times. Such an increase can be interpreted as the progressive consumption of $\mathrm{AChCl}$, the final products of the hydrolysis reaction being $\mathrm{ChCl}+\mathrm{AA}$. Impedance spectra recorded at $t_{R}=120 \mathrm{~min}$ (without and with UWB pulses at a $50 \mathrm{~Hz}$ repetition rate) were found very close to that obtained for the $\mathrm{ChCl}+\mathrm{AA}$ system alone (see Table 6). A complementary argument is given from the dielectric relaxation time $\tau_{\mathrm{HF}}$ (fig. 10), which decreases from the 
value for $\mathrm{AChCl}$ to that of $\mathrm{ChCl}$, the final product of the hydrolysis reaction. It is interesting to note that the parallel resistance $\mathrm{R}_{\mathrm{ad}}$ tends to infinite values after 40 minutes in the absence of pulses and not when pulses are applied. As $\mathrm{R}_{\mathrm{ad}}$ can be considered to be linked to the possible corrosion of gold electrode by the chloride ions at the very surface, infinite value of $\mathrm{R}_{\mathrm{ad}}$ would mean no more adsorbed chloride ions. This comment reinforces the fact that $\mathrm{AChCl}$ hydrolysis would be complete after 50-60 minutes.

Within the above considerations, for $t_{R} \leq t_{C R}$, using the sigmoid representation of $C_{o}\left(t_{R}\right)$ (see eq.13 and Table 5), a relative extent $\eta\left(\mathrm{t}_{\mathrm{R}}\right)$ of the $\mathrm{AChCl}$ hydrolysis reaction can be estimated (in \%) as:

$$
\eta\left(t_{R}\right)=100 \cdot \frac{\left(C_{o}\left(t_{R}\right)-C_{i n i}\right)}{\left(C_{\lim }-C_{i n i}\right)}
$$

The corresponding curves are plotted in the figure 11. The first remark to be done is the systematic decrease of the reaction efficiency at a given time when pulses are superimposed and when their repetition rate is increased. The second remark is the increasing slowing down of the reaction kinetics when the repetition rate is increased. For instance the hydrolysis reaction is practically inhibited for the $100 \mathrm{~Hz}$ repetition rate for times up to 40-50 min. Such a behaviour can be interpreted as a blocking effect of the UWB electromagnetic field of the enzyme catalysis of the $\mathrm{AChCl}$ hydrolysis reaction. This statement is based on the values of the static adsorption capacitance $\mathrm{C}_{0}$. A low value of $\mathrm{C}_{0}$ means a high surface coverage of electrodes by $\mathrm{AChCl}$ species reflecting a high bulk concentration. This is the situation at time zero. Without UWB pulses applied, an increase of $\mathrm{C}_{0}$ with the elapsed time is depicted, implying a decrease of the electrode surface coverage by $\mathrm{AChCl}$, to be correlated to a decrease of the $\mathrm{AChCl}$ bulk concentration, i.e. the progressive consumption of $\mathrm{AChCl}$ during the extent of hydrolysis reaction. On the contrary, with $100 \mathrm{~Hz}$ UWB pulses, $\mathrm{C}_{0}$ remains 
practically constant, indicating that the surface concentration, and then the bulk one, are not or a very few modified. Then the UWB pulses have no effect on the $\mathrm{AChCl}$ species leading to the conclusion that the observed inhibition effect is related to the action of UWB pulses on the AChE enzyme. It might be a conformational change of the AChE molecule, as it was observed for the $\beta$-lacto globulin under microwave irradiation [28] or for AChE submitted to low frequency electromagnetic fields [29].

Figure 11

\section{Conclusion}

Hydrolysis of $\mathrm{AChCl}$ catalyzed by $\mathrm{AChE}$ enzyme was studied by means of a broadband impedance technique covering the $40 \mathrm{~Hz}-4 \mathrm{GHz}$ frequency range with the same cell, without or with superimposed UWB pulses. The acquisition time for a full impedance spectrum being around 10 seconds allows one to follow the extent of the reaction. The response above $1 \mathrm{MHz}$ is related to the conductive and dielectric properties of the aqueous solution filling the cell. Below $100 \mathrm{kHz}$, the response is that of electrode impedance, at the gold/solution interfaces. It has been shown that the observed behaviour could be modelled by a dynamical adsorption desorption process of $\mathrm{AChCl}$, in equilibrium with the bulk. It means that the electrode impedance behaves as a sensor of the actual concentration of $\mathrm{AChCl}$ when the reaction is in progress. Experimental spectra were analyzed using an electrical circuit composed of two contributions in series representing the low and high frequency domains respectively. In both cases frequency dependent capacitances were introduced to account for the dielectric properties of the solution and for describing the time-dependent adsorption-desorption process. From the physical parameters involved in the model and extracted by numerical fitting, it was possible to image the extent of the hydrolysis reaction. The main feature is that 
the effect of superimposed UWB pulses was to slow down the reaction kinetics, the stronger this effect is the higher the pulses repetition rate is. The final conclusion is that the observed inhibition of $\mathrm{AChCl}$ hydrolysis in the presence of UWB pulses is due to the inhibition of the catalytic action of AChE enzyme, may be through a conformational change. Further work is needed to validate this proposal.

\section{$\underline{\text { Acknowledgements }}$}

The authors are very grateful to the French Direction Générale de l'Armement for the financial support of this study (Contract REI-DGA n ${ }^{\circ}$ 0534054). 


\section{REFERENCES}

[1] M. Markov, Thermal vs. nonthermal mechanisms of interactions between electromagnetic fields and biological systems. The mechanisms of the Biological Effect of Extremely High Power Pulses., Bioelectromagnetics Current Concepts, NATO Security Through Science Series, Volume 5, Ch.1, 2006, pp. 1-15, Springer Netherlands.

[2] R.P. Blackwell and R.D. Saunders, The effects of low-level radiofrequency and microwave radiation on brain tissue and animal behaviour, Int. J. Radiat. Biol. Relat. Stud. Phys. Med., 50, 761 (1986).

[3] K. Kajal, M. Ramovatar, K. Shivendra, R. Paulraj, V.H. Narayan and K.K. Kumar, Radiofrequency electromagnetic field exposure effects on antioxidant enzymes and liver function tests, Int. J. of Life Sci., 1, 233 (2012).

[4] S. Xu, Z. Zhou, L. Zhang, W. Zhang, Y. Wang, X. Wang, Y. Chen, C. Chen, M. He, G.. Zhang. and M. Zhong, Exposure to $1800 \mathrm{MHz}$ radiofrequency radiation induces oxidative damage to mitochondrial DNA in primary cultured neurons, Brain Research, 1311, 189 (2010).

[5] G. D'Inzeo, P. Bernardi, F. Eusebi, F. Grassi, C. Tamburello and B.M. Zani, Microwave effects on acetylcholine-induced channels in cultured chick myotubes, Bioelectromagnetics, 24, 363 (1988).

[6] J.A. D'Andrea, C.K. Chou, S.A. Johnston and E.A. Adair, Microwave effects on the nervous system, Bioelectromagnetics, 24(36), 5107 (2003).

[7] C. Gilbert, C. Pareige, A. Fourrier-Lamer, F. Maurel and O. Meyer, Characterization of acetylcholine hydrolysis under continuous and pulsed microwaves radiation using broadband dielectric measurement, PIERS Proc., pp. 1132-1136 (2009).

[8] C. Gilbert, Instrumentation hyperfréquence pour l'étude de cinétiques de réactions biochimiques en présence d'un champ électromagnétique de forte intensité. Interprétation physique des résultats., PhD thesis, P. \& M. Curie University, Paris VI, April 29th 2011.

[9] A. Silve, R. Vezinet and L.M. Mir, Nanosecond-duration electric pulse delivery in vitro and in vivo: Experimental considerations, IEEE Transactions on Instrumentation and Measurement, 61(7), 1945 (2012).

[10] S. Holden, R. Inns, C. Lindsay, J. Tatersall, P. Rice and J.L. Hambrook, Ultra wideband (UWB) radio-frequency $(R F)$ bioeffects research at DERA Porton Down., in International Conference on Ultra Wideband, Short-Pulse Electromagnetics 5, 2000, Edinburgh, Scotland, pp. 739-747, P.D. Smith and S.R. Cloude Editors, Kluwer Academic Pub., 2002.

[11] K. Schoenbach, S.J. Beebe and E.S. Buescher, Intracellular effect of ultra short electrical pulses, Bioelectromagnetics, 22(6), 440 (2001).

[12] D. Arnaud-Cormos, P. Leveque, Y.H. Wu, J.M. Sanders, M.A. Gundersen and P.T. Vernier, Micro chamber setup characterization for nanosecond pulsed electric field exposure, IEEE Transactions on Biomedical Engineering, 58(6), 1656 (2011). 
[13] N. Belhadj-Tahar and A. Fourrier-Lamer, Broad-band analysis of a coaxial discontinuity used for dielectric measurements, IEEE Trans. Microwave Theory Tech., vol. MTT-34 (3) 346 (1986).

[14] J.A. Nelder and R. Mead, A simplex method for function minimization, Computer J., 7, 308 (1965).

[15] A.J. Bard and L.R. Faulkner, Electrochemical Methods : Fundamental and Applications, $2^{\text {nd }}$ ed.; John Wiley \& Sons: New York, 2001.

[16] G.H. Haggis, J.B. Hasted and T.J. Buchanan, The dielectric properties of water in solutions, J. Chem. Phys., 20, 1452 (1952).

[17] J. Barthel and R. Buchner, Dielectric permittivity and relaxation of electrolyte solutions and their solvents, Chem. Soc. Rev., 21, 263 (1992).

[18] K. Nörtemann, J. Hilland and U. Kaatze, Dielectric properties of aqueous $\mathrm{NaCl}$ solutions at microwave frequencies, J. Chem. Phys. A, 101, 6864 (1997).

[19] A. Lyashchenko and A.Yu. Zasetsky, Complex dielectric permittivity and relaxation parameters of concentrated aqueous electrolyte solutions in millimeter and centimeter wavelength range, J. Molecular Liquids, 77, 61 (1998).

[20] A. Lyashchenko and A. Lileev, Dielectric relaxation of water in hydration shells of ions, J. Chem. Eng. Data, 55, 2008 (2010).

[21] W. Wachter, S. Fernandez, R. Buchner and G. Hefter, Ion association and hydration in aqueous solutions of $\mathrm{LiCl}$ and $\mathrm{Li}_{2} \mathrm{SO}_{4}$ by dielectric spectroscopy, J. Phys. Chem. B, 111, 9010 (2007).

[22] T. Pajkossy, Capacitance dispersion on solid electrodes : anion adsorption studies on gold single crystal electrodes, Solid State Ionics, 94, 123 (1997).

[23] Z. Kerner and T. Pajkossy, Measurement of adsorption rates of anions on Au(111) electrodes by impedance spectroscopy, Electrochim. Acta, 47, 2055 (2002).

[24] W. Lorenz, Über die Geschwindigkeit der Adsorption und der zweidimensionalen Assoziation höherer Fettsäuren an der Grenzfläche Quecksilber Elektrolytlösung, Z. Elektrochem., 62, 192 (1958).

[25] C. Cachet, H. Cachet and J.C. Lestrade, The analysis of impedance data related to the adsorption of neutral organic compounds at a mercury electrode, Electroanal. Chem. \& Interfacial Electrochem., 32, App.5-8 (1971).

[26] C. Cachet, H. Cachet, I. Epelboin and J.C. Lestrade, Tension superficielle à l'interface mercure-solution et cinétique d'adsorption de substances organiques, Electroanal. Chem. \& Interfacial Electrochem., 46, 363 (1973).

[27] R. Buchner, J. Barthel and J. Stauber, The dielectric relaxation of water between $0^{\circ} \mathrm{C}$ and $35^{\circ} \mathrm{C}$, Chem. Phys. Lett., 306, 57 (1999).

[28] H. Bohr and J. Bohr, Microwave enhanced kinetics observed in Optical Rotational Dispersion studies of a protein, Bioelectromagnetics, 21, 68 (2000). 
[29] E. Fathi and R. Farahzadi, Effect of electromagnetic field on AchE activity: in vitro study, African J. of Biochemistry Research, 6(1) 8 (2012). 


\section{FIGURES CAPTIONS}

Figure 1: Simplified scheme of the hydrolysis reaction of $\mathrm{AchCl}$ in the presence of the $\mathrm{AChE}$ enzyme.

Figure 2: Experimental set-up for broadband impedance spectroscopy measurements with superimposed UWB pulses. Practical frequency domain for measurements on aqueous systems for the three Agilent analysers used: $4294(40 \mathrm{~Hz}-50 \mathrm{MHz}) ; 4291(50 \mathrm{MHz}-1 \mathrm{GHz})$; E8364C (1-4 GHz). UWB pulses were delivered by a Kentec Special $1 \mathrm{kV}$ (max) pulser.

Figure 3: View of the cell used for broadband impedance measurements on liquids.

Figure 4: Nyquist diagrams recorded at increasing reaction times in the absence of superimposed UWB pulses: (a) impedance spectra; (b) same data but in the admittance representation.

Figure 5: Effect of superimposed UWB pulses at 50 and $100 \mathrm{~Hz}$ repetition rate upon Nyquist admittance diagrams recorded at about 70 minutes with respect to the diagrams obtained at times 0 and 70 minutes without superimposed pulses.

Figure 6: Equivalent electrical circuit used to fit the impedance response over the frequency range $40 \mathrm{~Hz}-1 \mathrm{GHz}$ with the elements given by Eqs. 6-12.

Figure 7: Relative variations of the electrolyte resistance as a function of the elapsed reaction time without and with superimposed UWB pulses at 10,50 and $100 \mathrm{~Hz}$ repetition rates.

Figure 8: Evolution of the diffusion time characterizing adsorption kinetics as a function of the elapsed reaction time without and with superimposed UWB pulses at 10,50 and $100 \mathrm{~Hz}$ repetition rates. When $\mathrm{AChCl}$ hydrolysis is complete, $\mathrm{AChCl}$ is progressively replaced by $\mathrm{ChCl}$ in the adsorption process at times longer than 70-80 minutes.

Figure 9: Evolution of the zero frequency adsorption capacitance as a function of the elapsed reaction time without and with superimposed UWB pulses at 10, 50 and $100 \mathrm{~Hz}$ repetition rates. When $\mathrm{AChCl}$ hydrolysis is complete, $\mathrm{AChCl}$ is progressively replaced by $\mathrm{ChCl}$ in the adsorption process at times longer than 70-80 minutes.

Figure 10: Decrease of the dielectric relaxation time with the elapsed reaction time without and with superimposed UWB pulses at a $50 \mathrm{~Hz}$ repetition rate, from the value corresponding to $\mathrm{AChCl}$ to the one corresponding to $\mathrm{ChCl}$.

Figure 11: Extent of the $\mathrm{AChCl}$ hydrolysis reaction in relative units evaluated from the adsorption capacitance data using Eq. 14. 
<smiles>CC(=O)OCC[N+](C)(C)C</smiles>

Acetylcholine Chloride Substrate
$\mathrm{Cl}^{-}+\mathrm{H}_{2} \mathrm{O} \stackrel{\mathrm{AChE}}{\longrightarrow}$

\section{Enzyme}

Catalyst

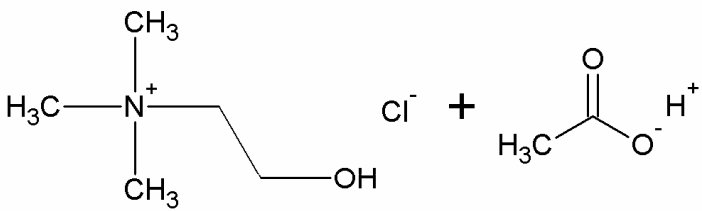

Choline Chloride Product 1
Acetic Acid

Product 2

Figure 1 


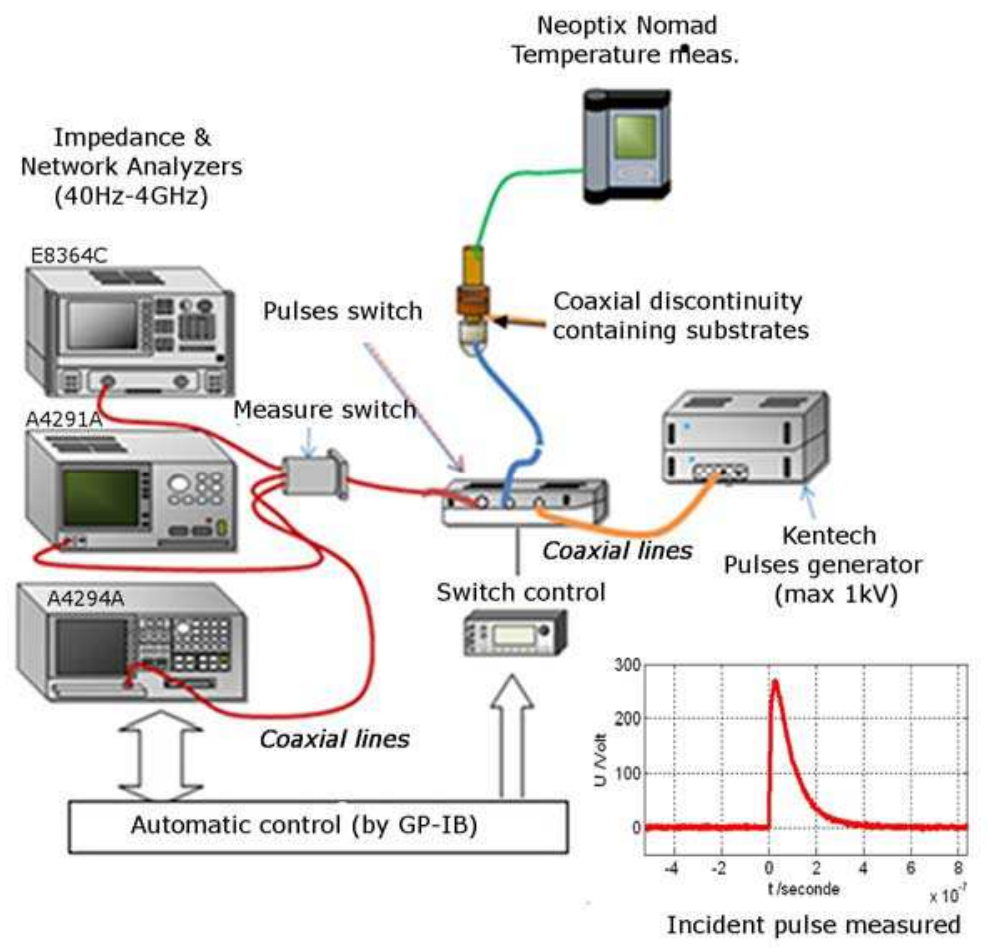

Figure 2 


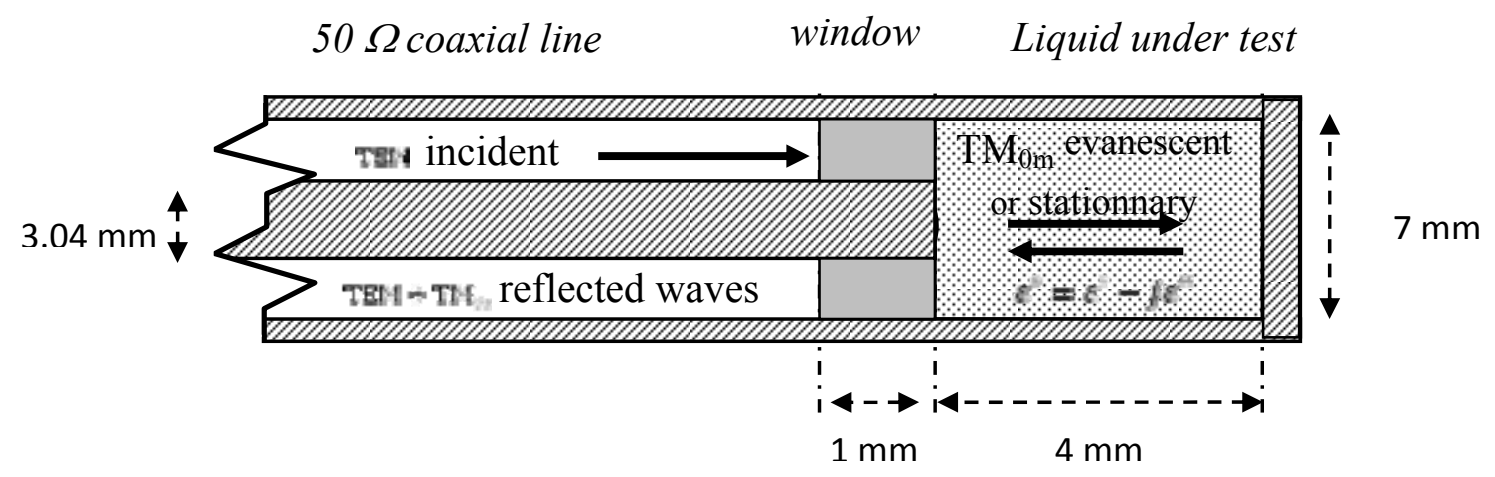

Figure 3 

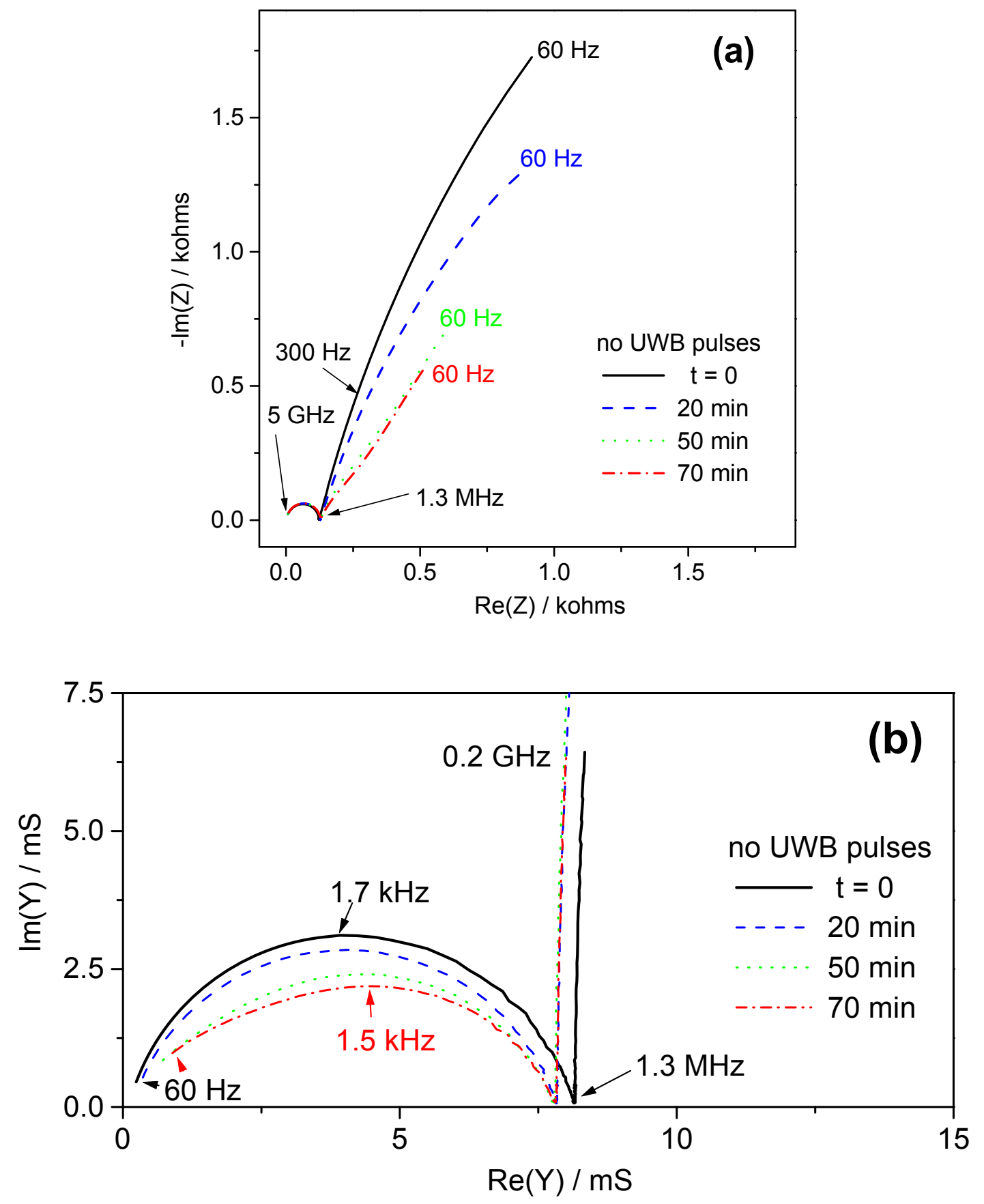

Figure 4 


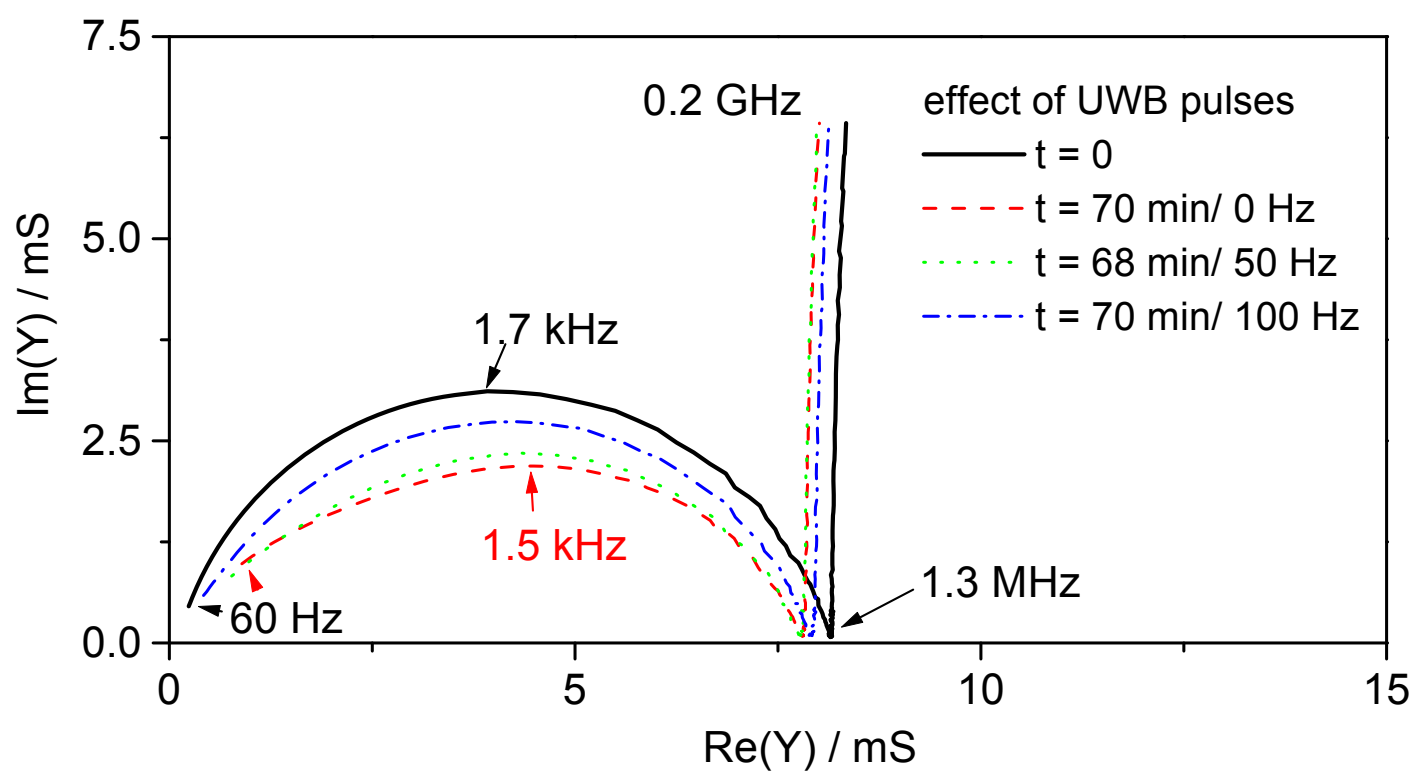

Figure 5 


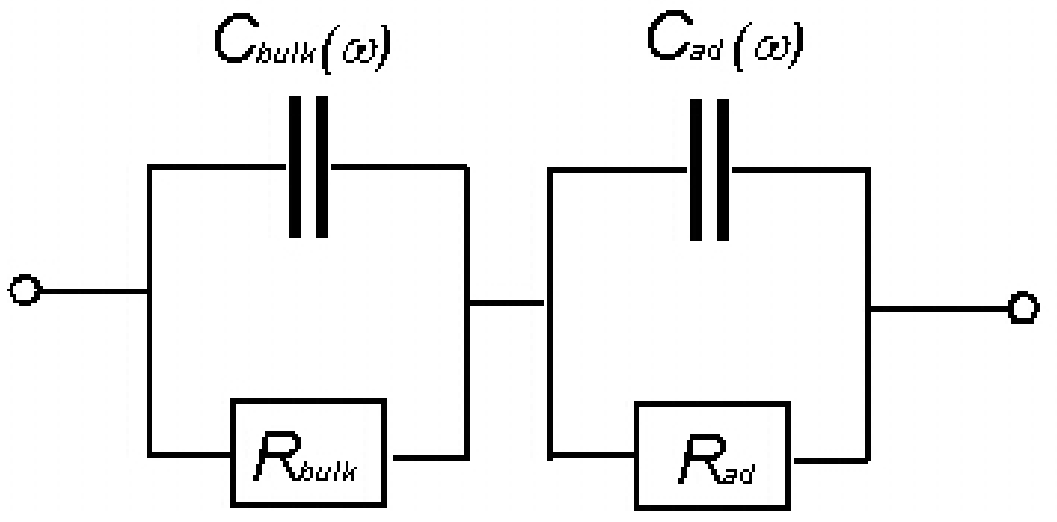

Figure 6 


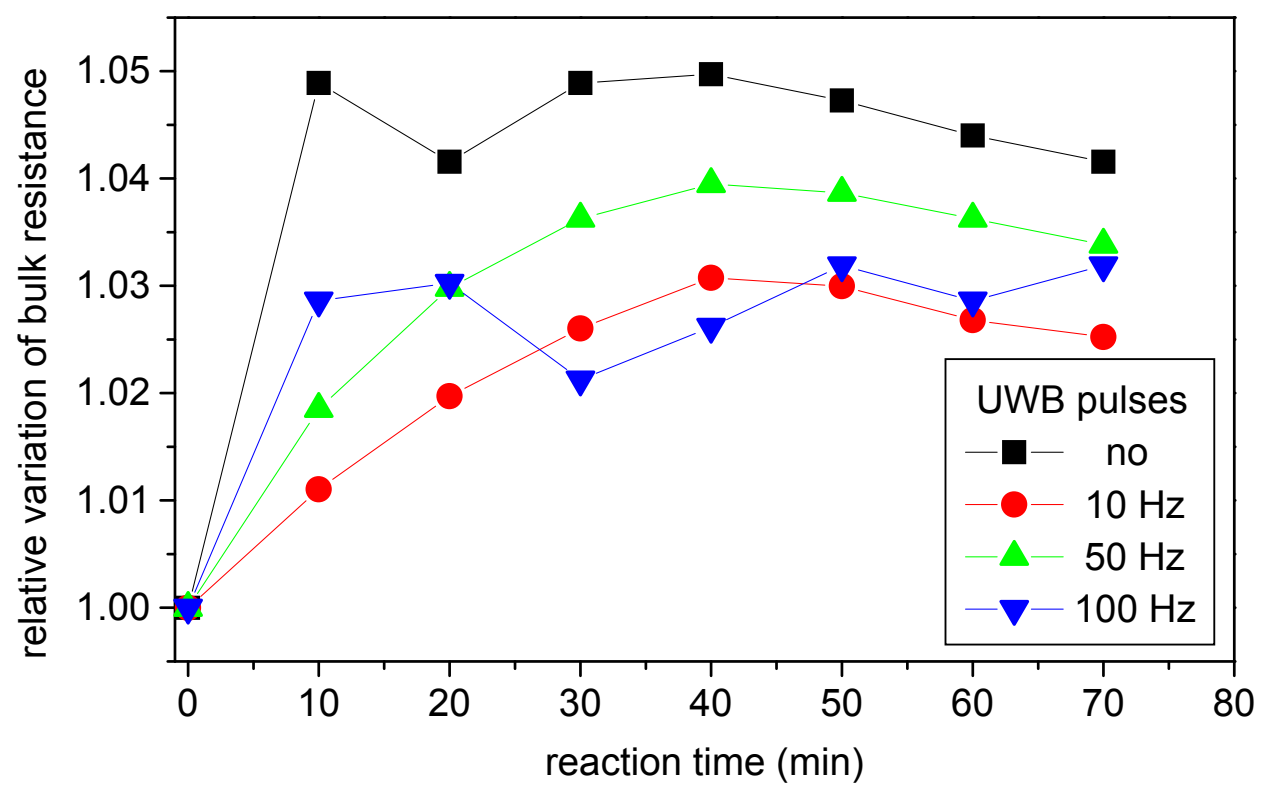

Figure 7 


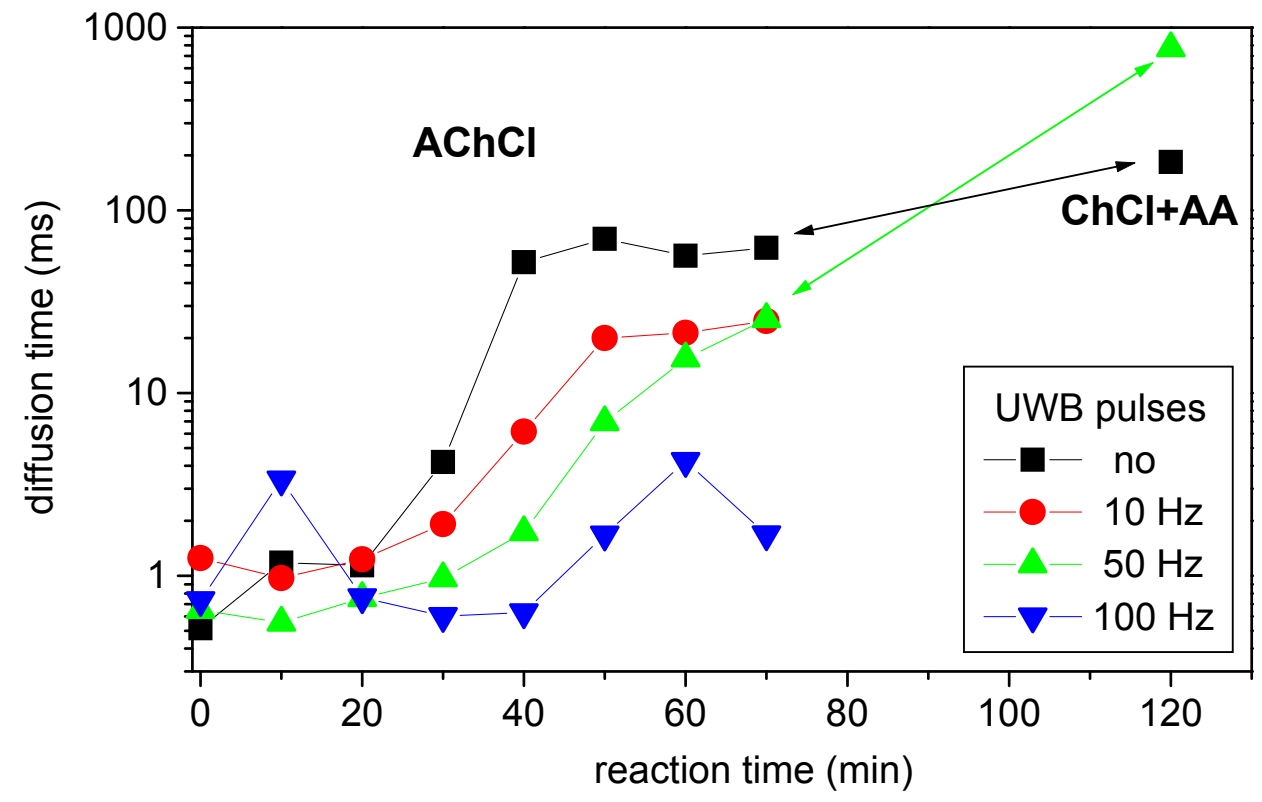

Figure 8 


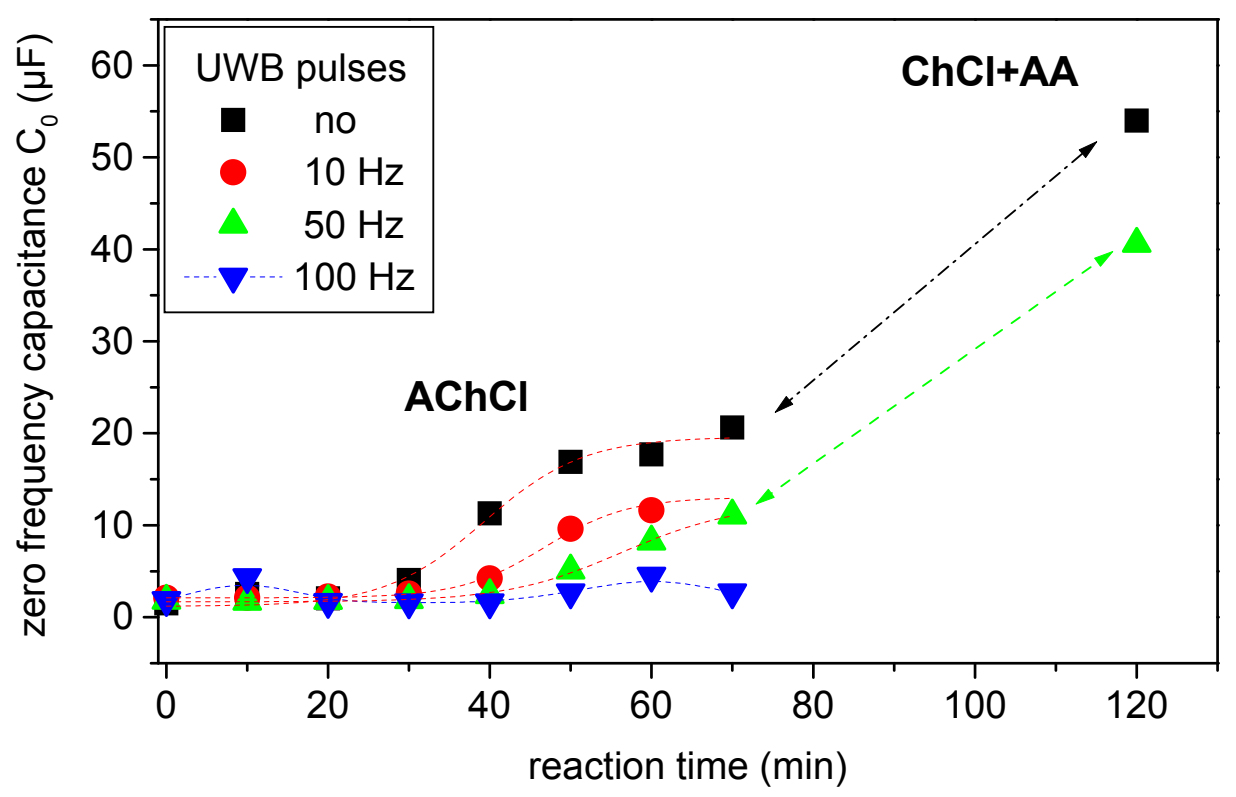

Figure 9 


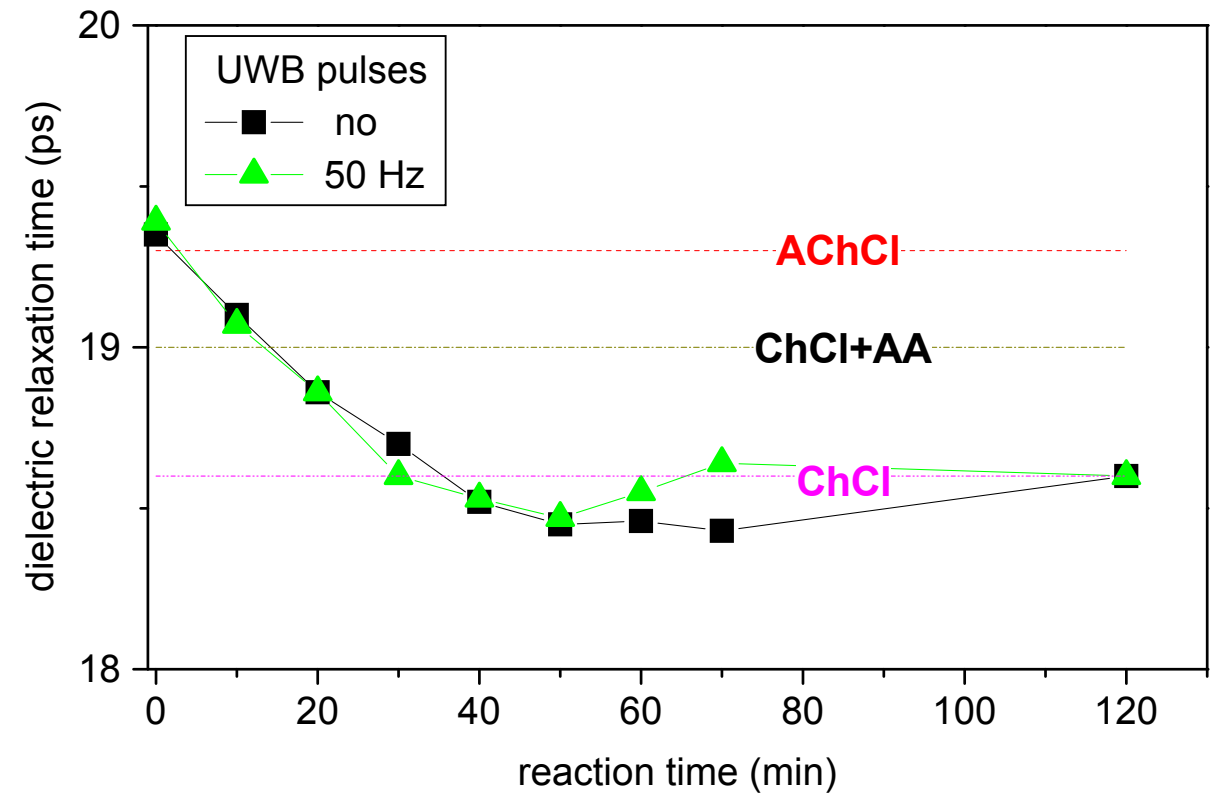

Figure 10 




Figure 11 


\section{TABLES}

\begin{tabular}{|c|c|c|c|c|c|c|c|c|}
\hline $\begin{array}{c}\text { no pulses } \\
\text { time/min }\end{array}$ & $\begin{array}{c}\mathbf{R}_{\text {bulk }} \\
\mathbf{o h m}\end{array}$ & $\begin{array}{c}\mathbf{R}_{\mathbf{a d}} \\
\mathbf{o h m}\end{array}$ & $\begin{array}{c}\mathbf{C}_{\infty} \\
\boldsymbol{\mu} \mathbf{F}\end{array}$ & $\begin{array}{c}\mathbf{C}_{\mathbf{0}} \\
\boldsymbol{\mu} \mathbf{F}\end{array}$ & $\begin{array}{c}\boldsymbol{\tau}_{\mathbf{D}} \\
\mathbf{m s}\end{array}$ & $\begin{array}{c}\tau_{\mathbf{H F}} \\
\mathbf{p s}\end{array}$ & $\boldsymbol{\varepsilon}_{\mathbf{s}}$ & S.D. \\
\hline 0 & 122.7 & 6893 & 0.41 & 1.51 & 0.52 & 19.4 & 78.6 & 1.0668 \\
\hline 10 & 128.6 & 2066 & 0.36 & 2.42 & 1.00 & 19.1 & 78.6 & 1.0236 \\
\hline 20 & 127.8 & 5126 & 0.43 & 2.06 & 1.14 & 18.9 & 78.8 & 1.1353 \\
\hline 30 & 128.7 & 15000 & 0.34 & 4.05 & 4.20 & 18.7 & 78.6 & 1.7250 \\
\hline 40 & 128.8 & 18300 & 0.45 & 11.3 & 52.0 & 18.5 & 78.8 & 1.1952 \\
\hline 50 & 128.5 & $10^{10}$ & 0.40 & 16.9 & 69.9 & 18.4 & 78.6 & 1.0244 \\
\hline 60 & 128.1 & $10^{10}$ & 0.36 & 17.7 & 56.4 & 18.5 & 78.5 & 0.9163 \\
\hline 70 & 127.8 & $10^{10}$ & 0.32 & 20.6 & 62.4 & 18.4 & 78.8 & 0.9925 \\
\hline 120 & 127.5 & $10^{10}$ & 0.42 & 54.0 & $184\left(^{\mathrm{a}}\right)$ & 18.6 & 78.1 & 1.0300 \\
\hline
\end{tabular}

$\left.{ }^{\mathrm{a}}\right): \tau_{\mathrm{H}}=1.15 \mathrm{~ms}$

Table 1: Fitted parameters of impedance spectra according to the electrical model depicted in Fig. 6 in the absence of superimposed pulses. $\mathrm{C}_{\text {cell }}=0.078 \pm 0.002 \mathrm{pF}$. For the data at 120 $\min$, both $\tau_{\mathrm{D}}$ and $\tau_{\mathrm{H}}$ had to be taken into account.

\begin{tabular}{|c|c|c|c|c|c|c|c|c|}
\hline $\begin{array}{c}\text { pulses 10 Hz } \\
\text { time/min }\end{array}$ & $\begin{array}{c}\mathbf{R}_{\text {bulk }} \\
\mathbf{o h m}\end{array}$ & $\begin{array}{c}\mathbf{R}_{\mathbf{a d}} \\
\mathbf{o h m}\end{array}$ & $\begin{array}{c}\mathbf{C}_{\infty} \\
\boldsymbol{\mu F}\end{array}$ & $\begin{array}{c}\mathbf{C}_{\mathbf{0}} \\
\boldsymbol{\mu} \mathbf{F}\end{array}$ & $\begin{array}{c}\boldsymbol{\tau}_{\mathbf{D}} \\
\mathbf{m s}\end{array}$ & $\begin{array}{c}\tau_{\mathbf{H F}} \\
\mathbf{p s}\end{array}$ & $\boldsymbol{\varepsilon}_{\mathbf{s}}$ & S.D. \\
\hline 0 & 126.8 & 7162 & 0.50 & 2.11 & 1.25 & 18.0 & 79.9 & 1.3172 \\
\hline 10 & 128.2 & 7052 & 0.48 & 2.11 & 0.97 & 17.7 & 79.9 & 1.2386 \\
\hline 20 & 129.3 & 6549 & 0.48 & 2.25 & 1.23 & 17.4 & 79.9 & 1.2637 \\
\hline 30 & 130.1 & 5956 & 0.48 & 2.56 & 1.92 & 17.2 & 79.8 & 1.2933 \\
\hline 40 & 130.7 & 6190 & 0.42 & 4.22 & 6.16 & 17.1 & 79.8 & 1.3024 \\
\hline 50 & 130.6 & 11694 & 0.44 & 9.61 & 20.0 & 17.0 & 79.8 & 1.2063 \\
\hline 60 & 130.2 & 12814 & 0.39 & 11.6 & 21.4 & 17.0 & 79.8 & 1.1987 \\
\hline 70 & 130.0 & 11881 & 0.36 & 13.4 & 24.8 & 17.0 & 79.8 & 1.1949 \\
\hline
\end{tabular}

Table 2: as Table 1, but in the presence of superimposed UWB pulses at the $10 \mathrm{~Hz}$ repetition rate. 


\begin{tabular}{|c|c|c|c|c|c|c|c|c|}
\hline $\begin{array}{c}\text { pulses 50 Hz } \\
\text { time/min }\end{array}$ & $\begin{array}{c}\mathbf{R}_{\text {bulk }} \\
\mathbf{o h m}\end{array}$ & $\begin{array}{c}\mathbf{R}_{\mathbf{a d}} \\
\mathbf{o h m}\end{array}$ & $\begin{array}{c}\mathbf{C}_{\infty} \\
\boldsymbol{\mu F}\end{array}$ & $\begin{array}{c}\mathbf{C}_{\mathbf{0}} \\
\boldsymbol{\mu F}\end{array}$ & $\begin{array}{c}\boldsymbol{\tau}_{\mathbf{D}} \\
\mathbf{m s}\end{array}$ & $\begin{array}{c}\boldsymbol{\tau}_{\mathbf{H F}} \\
\mathbf{p s}\end{array}$ & $\boldsymbol{\varepsilon}_{\mathbf{s}}$ & S.D. \\
\hline 0 & 124.1 & 6381 & 0.44 & 1.80 & 0.65 & 19.4 & 78.2 & 1.0411 \\
\hline 10 & 126.4 & 8356 & 0.42 & 1.69 & 0.55 & 19.1 & 78.2 & 0.9807 \\
\hline 20 & 127.8 & 7504 & 0.43 & 1.78 & 0.76 & 18.9 & 78.2 & 1.0097 \\
\hline 30 & 128.6 & 6571 & 0.43 & 1.88 & 0.97 & 18.6 & 78.0 & 1.0387 \\
\hline 40 & 129.0 & 4844 & 0.44 & 2.41 & 1.73 & 18.5 & 77.9 & 1.0514 \\
\hline 50 & 128.9 & 4276 & 0.51 & 5.08 & 6.93 & 18.5 & 77.9 & 1.0279 \\
\hline 60 & 128.6 & 5284 & 0.40 & 8.23 & 15.5 & 18.5 & 77.9 & 1.0254 \\
\hline 70 & 128.3 & 6432 & 0.38 & 11.1 & 25.4 & 18.6 & 78.0 & 1.0234 \\
\hline 120 & 126.6 & 13280 & 0.30 & 40.6 & 244 & 18.6 & 78.5 & 1.0333 \\
\hline
\end{tabular}

Table 3 : as Table 1, but in the presence of superimposed UWB pulses at the $50 \mathrm{~Hz}$ repetition rate.

\begin{tabular}{|c|c|c|c|c|c|c|c|c|}
\hline $\begin{array}{c}\text { Pulses } 100 \mathrm{~Hz} \\
\text { time/min }\end{array}$ & $\begin{array}{l}\mathbf{R}_{\text {bulk }} \\
\text { ohm }\end{array}$ & $\begin{array}{l}\mathbf{R}_{\mathrm{ad}} \\
\mathbf{o h m}\end{array}$ & $\begin{array}{l}\mathbf{C}_{\infty} \\
\boldsymbol{\mu F}\end{array}$ & $\begin{array}{l}\mathbf{C}_{0} \\
\mu F\end{array}$ & $\begin{array}{l}\tau_{\mathrm{D}} \\
\mathrm{ms}\end{array}$ & $\begin{array}{c}\tau_{\mathrm{HF}} \\
\mathrm{ps}\end{array}$ & $\varepsilon_{\mathrm{s}}$ & S.D. \\
\hline 0 & 122.3 & 6583 & 0.442 & 1.88 & 0.73 & 19.2 & 78.8 & 1.0076 \\
\hline 9 & 125.8 & 2334 & 0.378 & 4.33 & 3.36 & 18.6 & 77.9 & 1.0220 \\
\hline 19 & 126.0 & 8960 & 0.464 & 1.64 & 0.76 & 18.6 & 78.1 & 0.5992 \\
\hline 24 & 124.9 & 8120 & 0.429 & 1.58 & 0.60 & 18.6 & 78.2 & 0.9930 \\
\hline 30 & 125.5 & 7655 & 0.423 & 1.59 & 0.63 & 18.5 & 78.1 & 1.0073 \\
\hline 50 & 126.2 & 4152 & 0.414 & 2.68 & 1.68 & 18.4 & 77.9 & 1.0259 \\
\hline 60 & 125.8 & 3366 & 0.400 & 4.49 & 4.25 & 18.9 & 77.9 & 1.0452 \\
\hline 70 & 126.2 & 4152 & 0.414 & 2.68 & 1.68 & 18.4 & 77.9 & 1.0259 \\
\hline
\end{tabular}

Table 4 : as Table 1, but in the presence of superimposed UWB pulses at the $100 \mathrm{~Hz}$ repetition rate. 


\begin{tabular}{|c|c|c|c|c|}
\hline $\begin{array}{c}\text { repetition } \\
\text { rate } \mathrm{Hz}\end{array}$ & $\begin{array}{c}\mathrm{C}_{\mathrm{ini}} \\
\mu \mathrm{F}\end{array}$ & $\begin{array}{c}\mathrm{C}_{\mathrm{lim}} \\
\mu \mathrm{F}\end{array}$ & $\begin{array}{c}\mathrm{t}_{1 / 2} \\
\min \end{array}$ & $\begin{array}{c}\mathrm{dt}_{\mathrm{R}} \\
\min \end{array}$ \\
\hline 0 & 1.2 & 19.6 & 39 & 6.1 \\
\hline 10 & 2.1 & 13.1 & 47 & 5.2 \\
\hline 50 & 1.7 & 12.4 & 56 & 7.2 \\
\hline $100(*)$ & 1.8 & 3.6 & - & - \\
\hline
\end{tabular}

$(*)$ estimation to the naked eye.

Table 5 : Parameters of the sigmoid curve representing the variations of the adsorption capacitance $\mathrm{C}_{0}$ with the reaction time according to Eq. 13 .

\begin{tabular}{|c|c|c|c|c|c|c|c|c|}
\hline System & $\mathbf{R}_{\text {bulk }}$ & $\mathbf{R}_{\mathbf{a d}}$ & $\mathbf{C}_{\infty}$ & $\mathbf{C}_{\mathbf{0}}$ & $\boldsymbol{\tau}_{\mathbf{D}}$ & $\tau_{\mathbf{H F}}$ & $\boldsymbol{\varepsilon}_{\mathbf{s}}$ & S.D. \\
$\mathbf{( 5 0} \mathbf{~ m M )}$ & $\mathbf{o h m}$ & $\mathbf{o h m}$ & $\boldsymbol{\mu} \mathbf{F}$ & $\boldsymbol{\mu} \mathbf{F}$ & $\mathbf{m s}$ & $\mathbf{p s}$ & & \\
\hline $\mathrm{AchCl}$ & 122.6 & $10^{10}$ & 0.427 & 4.71 & 30.9 & 20.0 & 78.8 & 1.3664 \\
\hline $\mathrm{ChCl}$ & 123.0 & $10^{10}$ & 0.500 & 5.45 & 29.0 & 18.6 & 74.0 & 1.1406 \\
\hline $\mathrm{ChCl}+\mathrm{AA}$ & 122.7 & $10^{10}$ & 0.547 & 59.4 & $393\left(^{\mathrm{a}}\right)$ & 19.0 & 77.9 & 1.1494 \\
\hline
\end{tabular}

$\left(^{\mathrm{a}}\right): \tau_{\mathrm{H}}=3.60 \mathrm{~ms}$

Table 6: Fitted parameters of impedance spectra of individual systems ( $\mathrm{AChCl}, \mathrm{ChCl}, \mathrm{ChCl}+$ AA, measured in the absence of AChE) according to the electrical model depicted in Fig. 6 . For $\mathrm{ChCl}+\mathrm{AA}$, both $\tau_{\mathrm{D}}$ and $\tau_{\mathrm{H}}$ had to be taken into account. 